\title{
INFORMAL LEARNING FOR TEACHERS' PROFESSIONAL DEVELOPMENT AT SCHOOL: OPPORTUNITIES AND CHALLENGES
}

\author{
Oskars Kaulens \\ University of Latvia, Latvia
}

\begin{abstract}
Professional environment has changed dramatically during recent decades: it has become more dynamic, more complex and less structured. These changes are also applied to schools where teachers are required to work more with students and are given new responsibilities relating to management of the school. Also, the role of teachers in the classroom and the requirements for assessing teachers' professional performance have changed significantly. Formal learning carried out in a structured, purpose-led process usually does not meet the real needs of teachers' professional development, does not improve teachers' professional performance in classroom and does not have direct positive influence on students' learning outcomes. The formal learning of teachers is organised outside the real context teachers work in and does not allow them to reflect on their experience. Informal learning is offered as an alternative form of teachers' professional development that includes individual and collective learning activities which are carried inside or outside the school and are based on learning from other professionals, participating in informal conversations or sharing experience without a specific learning goal and process manager.

The aim of the literature review is to summarize the theoretical approaches of informal learning, focusing on several aspects of informal learning for teachers' professional development: different ways how informal learning can be implemented inside the school; factors that promote and hinder teachers' professional development through informal learning; the benefits and risks faced by teachers who are improving their professional competence by engaging in informal learning activities.
\end{abstract}

Keywords: Formal learning; Informal learning; Professional development; Learning at the workplace.

\section{Introduction}

The new requirements in education determine important changes that are happening not only in the curriculum students have to study at school but also in the teaching methods and strategies which teachers have to use to meet these requirements. Depending on the fact how effectively teachers learn new strategies, gain an understanding of the principles of curriculum 
design and change their own perceptions about students' learning, it is possible to make conclusions about the sustainability of educational reforms and their impact on the quality of education. Many educational reforms have failed because teachers have been indifferent or refusing to change according to their prior learning experiences as students and their attitudes towards continuous professional development (Hoekstra \& Korthagen, 2011).

Teachers' professional development needs are directly determined not only by structural reforms taking place in educational system but also by the changes in professional environment. The environment at schools has become more complex and dynamic, characterized by the need to address more diverse and less structured problems, and hence greater uncertainty (McLagan, 2008). As a result of these changes, the demands and responsibilities of teachers also have changed: teachers have to teach classes with an increasing number of students; there are more students with emotional, social and learning difficulties. Similarly, in schools, decisions are increasingly adopted in a decentralized way, with the direct involvement of teachers in school management issues (Lohman, 2000). Teachers need to improve their knowledge of curriculum and teaching methodology to ensure that students' learning outcomes meet the modern requirements (Jurasaite-Harbison \& Rex, 2013).

In order to meet new learning needs of teachers, increase their motivation and provide a constructive feedback on their results, it is necessary to change the way teachers' professional development is organized at the workplace. The traditional model of structured, formalized and purposefully directed teacher learning does not always provide the necessary skills and knowledge to help them teach students in accordance with the new requirements. Often, such development is carried out formally, without a direct long-term impact on teachers' performance and students' learning outcomes (Sprott, 2019). However, the main goal of teachers' professional development is to help students to learn, to gain a diverse learning experience and improve their learning skills and academic achievements (DiPaola \& Hoy, 2014).

Informal learning is offered as an alternative form of teachers' professional development model. It includes a self-initiated, voluntary learning activities at the workplace where mutual interaction between teachers helps to improve their knowledge and skills on specific issues. Usually informal learning is not externally managed and structured process, it is based on intensive use of the previous work experience and reflection on it (Lohman, 2006). Studies conducted so far have concluded that about $90 \%$ of teachers' real-time learning takes place informally, rather than through participation in structured learning activities (Lohman, 2000). 


\section{Methodology}

The full-text scientific articles available in the EBSCOhost database in English, published between 2010 and 2019, are used in the literature review. Scientific articles have been selected using the following keywords: informal learning AND professional development, AND teachers, AND school.

According to the chosen keywords, 25 scientific articles have been identified in the database for the selected period of time, the content of which is related to the teachers' informal learning at the workplace. 10 articles have been selected for in-depth analysis which are directly related to the informal learning of teachers inside the general schools.

The literature review does not include the publications on teachers' informal learning in other educational settings, such as higher educational institutions or online. Other scientific articles referenced in the selected articles and available in EBSCOhost or other free access databases have been used in the literature review. The use of these articles is necessary for a deeper understanding of the process of informal learning inside the school, with a reference to the authors who have started to research informal learning in the context of teachers' professional development.

The aim of the literature review is to explore the topicalities of informal learning in the general schools and to identify the key benefits and risks that informal learning can bring into professional development of teachers. To reach this goal, the insights expressed in the articles have been systematized and described in 4 categories: the characteristics and the forms of teachers' informal learning at school; factors that promote and hinder informal learning at school; the benefits of informal learning at school; the challenges of informal learning at school.

\section{Teachers' informal learning at the workplace}

The quality of education depends on how skilled and motivated teachers are to improve their professional knowledge and skills throughout all their career (Vanblaere \& Devos, 2016). It is related to a rapidly changing professional environment, where new requirements for school graduates are appearing: students have to have collaborative skills, problem-solving skills, creative thinking, critical thinking etc. The teachers' individual competence and professionalism determine how successful the reforms in the education system will be and how high the level of students learning outcomes will be (Cheng, 2017). During the previous decades there has been a growing and continuous demand for teachers to improve their knowledge and skills on curriculum and teaching methodology (JurasaiteHarbison \& Rex, 2013). 
Teachers have to be ready to improve their professional performance, to challenge their existing perceptions and mindset about teaching and learning, and become learning agents for themselves and their students. Thus, the traditional way of teachers' professional development, according to the principle "one size fits all" workshops, is no longer able to meet the real professional development needs of teachers (Patton, Parker \& Tannehill, 2015). Formal professional development is not capable to eliminate the growing gap between the knowledge and skills teachers need in the real working environment and those that can be learned through formal training activities (Tynjälä, 2008).

Participation in formal learning activities (in-service training courses, seminars, lectures, workshops etc.) is still a common practice for teachers' professional development in schools. However, the impact of formal learning experience on teachers' performance in the classroom is limited. Researchers have concluded that teachers rarely use the methods and techniques they have learned in formal trainings (Wideen, Mayer-Smith \& Moon, 1998). This is due to the fact that during formal learning activities there is no time for purposeful reflection on teachers' professional activities to make a transfer from the new curriculum to their professional practice.

Teachers report that they learn much more in their daily work with students, independently experimenting with teaching and learning strategies, assessing their impact on students' learning outcomes and learning from their mistakes (Lohman \& Woolf, 2001). Substantial part of the teachers' professional learning takes place in the classroom, working with students where teachers spend the most of the time of their practice. Therefore, teachers have to be professionals who are learning from their previous experience (Lund, 2018), trying new strategies and reflecting on the results.

Informal learning is the acquisition of new professional knowledge and the development of skills outside the structured and institutionalized learning environment. It takes place in the process of voluntary cooperation and exchange of experience, where employees of one organization interact and learn from each other. Informal learning does not involve systematic, pre-planned repetition of routine activities, it is not structured and often does not have clearly defined learning goals (Marsick, Watkins, Callahan \& Volpe, 2009). The goal of informal learning is to provide continuous and goal-oriented professional development at the workplace, taking into account the real learning needs of the stakeholders and using the professional resources available within the organization (Tynjälä, 2008).

Informal learning is characterized by indirect, unplanned and voluntary learning, which does not highlight the person who teaches the new content (Eraut, 2004). Informal learning is implemented as a part of a daily learning 
process where teachers, through individual actions or collaboration, acquire the knowledge and skills they need in a concrete professional situation. The goal of such learning activities is not to learn and implement specific curriculum, and it does not take place in a learning environment specifically designed for learning purposes. Informal learning at school takes place through individual activities (getting acquainted with professional literature and observing classrooms of other teachers) and collective activities (conversations with colleagues, students and parents, mentoring programs, participation in teacher networks and learning groups) (Desimone, 2009).

During the activities of informal learning teachers have an opportunity to choose their own learning goals as well as the learning strategies they are going to use. In the process of informal learning, participants set learning goals themselves, determine how these goals will be achieved, and evaluate how the goals have been achieved (Cross, 2007). Usually, such professional development is based on a specific class or school context, which allows teachers to understand the real learning needs better, reflect on their experiences and learn from their colleagues (Richter, Kunter, Klusmann, Ludtke \& Baumert, 2011). Thus, teachers who want to develop their competencies through informal learning have to understand the context of their school and have to be ready to reflect on their own experience and practice with other teachers.

The goal of informal learning within a school is to make the knowledge and skills accumulated by individual people to a wider range of professionals available through the elements of social interaction. In this way, knowledge is constructed in a specific context, so it is more commonly used because it is directly related to the participant's personal experience than the knowledge acquired through formal learning outside the concrete context of the school (Eraut, 2004).

Unlike formal learning, where the acquisition of new professional knowledge and skills is an act of individual behavior, informal learning takes place within a learning community (Lave \& Wenger, 1991). In the context of the school, informal learning is an act of social participation, where teachers are learning from their own previous experience and expertise, which has been accumulated in the organization. In the model of informal learning, the experience of each teacher acquires value of learning potential which other colleagues can use to meet their learning needs.

Jurasaite-Harbison and Rex (2013) point out that informal learning takes place in several dimensions, for example, the authors distinguish proactive and reactive informal learning. In the framework of proactive learning, teachers themselves set their own learning goals; require regular advice and feedback from colleagues; independently seek and explore sources of information to prevent teaching-related problems. Meanwhile, 
reactive informal learning is an unintentional professional activity where teachers respond to situations that have already taken place; they do not set their own learning goals and start to learn from their colleagues when problems have already occurred. The authors also separate the individual and social dimension of informal learning, where the first focuses on individual activities to improve one's performance, while the other is dependent on collaboration with colleagues and joint participation in the assessment of collective experience.

Teachers pursue their professional development through different informal learning activities: they are collaborating with schools' leadership team and other teachers; sharing experience of teaching methods and techniques used with students; attending school meetings; observing classrooms of other colleagues; participating in learning group activities, etc. (Kwakman, 2003). In the school environment, informal learning also takes place between students and teachers, where both learn how to adapt, cooperate and respect each other. Teachers are thus acquainted with their students and understand their learning needs better (McNally, Blake \& Reid, 2009).

The above mentioned examples of informal learning provide intensive feedback, reception and use of feedback to improve the performance. However, teachers' informal learning at school is not always structured or implemented as an autonomous learning process. School leadership team often formalizes and structures informal learning to ensure its regularity and long-term impact on students' learning. Researches have shown that informal learning is more effective and consistent with school vision and goals if it is organized in a more formal framework, such as learning projects, where teachers jointly address and analyze specific learningrelated issues, learning from each other and finding common solutions (Poell , 2006). However, efforts to structure informal learning at school can disrupt existing social relationships among teachers and create a negative impact on mutual learning outcomes (Lohman, 2000).

\section{Factors influencing teachers' informal learning at the workplace}

The effectiveness of teachers' informal learning at school is influenced by individual factors related to teachers' willingness and ability to evaluate their professional experience, readiness to learn from other colleagues' experience and to use the feedback they receive to improve their performance. It is also affected by administrative factors related to the way in which professional development of teachers is organized and supervised at school, and what kind of professional resources are available to teachers to meet their current development needs (Carney, 2000). 
Informal learning is a multidimensional concept that includes organizational and personal elements as well as elements of interpersonal cooperation. Organizational factors are related to the availability of professional resources at school, such as the availability of the necessary information for teachers and the time available for them to learn from other colleagues; similarly, informal learning is influenced by the culture of the school's internal organization and the existing relationships of trust between teachers (Vanblaere \& Devos, 2016). Skills and knowledge, and the learning experience that teachers gain through informal learning at school, are influenced by the process of socialization that is based on the norms and values that exist within the school (Eraut, 2004).

Personal factors determine the ability of teachers to develop new knowledge and experience, learning from the experience of other professionals, willingness to try new teaching strategies, and learn from their personal mistakes. Interpersonal co-operation factors, on the other hand, are related to how co-operation between teachers is developed and maintained inside the school and how teachers make common agreements about their professional development needs and learning goals for their students (Vanblaere \& Devos, 2016). Informal learning is directly influenced by teachers' willingness to work together with their colleagues, which is determined by their understanding of learning goals students need to achieve (Patton, Parker \& Tannehill, 2015).

Lack of time is mentioned as one of the factors that can limit the outcomes of informal learning at school. The role and responsibilities of teachers have changed significantly over time, and teachers have more responsibilities that are not directly related to classroom work, so it is necessary to spend more time on purposeful professional development. Informal learning is effective if there is time that can be spent outside the classroom when teachers can meet for informal conversations, learn from each other and plan learning activities together (Lohman, 2006). It is important for teachers to have time and space where they can reflect on their experience and get to know other colleagues (Sprott, 2019).

The physical environment and infrastructure at school have a direct impact on the outcomes of informal learning for teachers. In situations where the physical distance between teachers' classrooms is high, teachers' access to mutual learning resources is restricted. As a result, professional isolationism develops, where each teacher acts autonomously and solves problems independently regardless of the amount of experience and knowledge already accumulated at school (Sprott, 2019). In order to avoid the teachers' isolationism, it is advisable to place closer teachers of the same grade or similar subjects in order to provide them an opportunity for informal consultations and exchange of experiences. 
The ability to learn from the experience of other professionals, both within and outside the school, directly determines the outcomes of informal learning. Researches have shown that teachers who are unable to interact with other colleagues to construct new knowledge and learn from others' experience are lagging behind those who can do it (Slotte \& Tynjala, 2003). Involvement of teachers in the informal learning process is determined by the open, positive and collaborative atmosphere at school and the readiness of teachers to engage with other colleagues (Wohlfahrt, 2018). In cases where the school internal environment is closed, and colleagues feel more like competitors than members of a unified learning community, informal learning becomes a formality without a direct impact on teachers' performance in the classroom and students' learning outcomes.

It is also important for teachers to reflect on their experience and to receive feedback from others, because during the informal learning new knowledge is constructed by evaluating previous experience to make decisions about the improvements to be made in the future. Regardless of the way in which the new knowledge is acquired, it is less important what teachers know, rather than how they can apply the acquired knowledge to new learning situations. In order to carry out this professional transfer, teachers need the skills to reflect on their experience, as well as receive and apply feedback in the short term to make specific improvements in their pedagogical practice, and systematically evaluate their progress in the long term (Eraut, 2004).

School leadership activities are also crucial for creating an informal learning environment and achieving results. Higher results are achieved by schools where school management is focused on creating a culture of teachers' collaboration and demonstrates an example of continuous professional development through learning from others' experiences (Cheng, 2017). School management, which helps teachers to recognize their professional development needs, encourages them to learn from the best practices and assesses teachers' performance not only in terms of student learning, but also in teacher's personal growth, creates a school as an effective learning community (Harris \& Jones, 2010).

For the school to become a professional learning community with continuous professional development of teachers, a culture of trust in the school is needed that provides openness among teachers and the opportunity to learn from the mistakes that have been made (Vaessen, van den Beemt \& de Laat, 2014). Researches have shown that teachers are better at their learning at school when school leadership and teachers have developed a common vision about professional development, created a system of shared responsibility for achieving goals, and maintained values and norms that ensure high quality social relationships among teachers (JurasaiteHarbison \& Rex, 2010). 


\section{Benefits of teachers' informal learning at the workplace}

Teachers' informal learning usually takes place at school, so teachers have the opportunity to learn in a real context, determining what content they want and how they are going to learn it. Teachers are given greater autonomy to define their own learning needs and they take full responsibility for the results of their professional development. Wohlfahrt (2018) points out that the biggest problem with formal professional development is that the curriculum that teachers study is not linked to a specific context and is not based on the real learning needs of teachers. In contrast, informal learning provides a direct link to the real challenges that teachers are facing in their everyday practice, so they are more open and motivated to learn how to solve these problems.

As a result of informal learning, the school is transformed into an effective learning organization where continuous professional development of teachers takes place, and each teacher's previous experience is seen as a value with important learning potential. In the learning organization, teachers are sharing their experiences and exchange pedagogical literature; they are helping to solve each other's professional problems; teachers are having discussions about professional issues and jointly looking for ways how to improve their performance by learning from the best practices in the organization (Wenger, McDermott \& Snyder, 2002). In schools that are based on the principles of a learning community, teachers are helping each other to identify the real needs of professional improvement (DuFour \& Eaker, 1998) as a result of an intensive exchange of experiences and reflection, providing the opportunity for them to learn practical and useful content. As a result of informal learning, the relationships of trust between teachers is strengthened and their sense of belonging to the community is promoted (Hanraets, Hulsebosch \& de Laat, 2011).

Informal learning is a natural way for teachers to improve their professional skills, which shows the results in a long term. If formal learning is implemented in the form of individual learning events, such as lectures or seminars, informal learning is the result of everyday activities carried out by teachers within the school. This means that informal learning is a continuous process of development through which teachers develop their expertise, acquire the necessary knowledge and develop skills (Vaasen, van den Beemt \& de Laat, 2014). That kind of learning leads to strong social relationships between teachers because every teacher is seen as a learning resource that can influence overall learning outcomes of the school.

Informal learning offers a variety of learning opportunities for teachers where everyone can choose the one that suits them best. The professional development of teachers can happen as giving advice for other colleagues; 
reflecting on their professional practice and analyzing the performance of other teachers; providing and receiving feedback from others; engaging in informal discussions on educational issues; commenting on opinions expressed by other professionals, etc. (Tammets, Pata \& Laanpere, 2013). It means that informal learning is more flexible than formal learning and can be adapted to a wider range of teachers' professional development needs (Eraut, 2004).

For informal learning to be effective and to achieve goals, teachers need the skills to provide, receive and apply feedback to improve their performance, reflect on their own and other learning experiences, critically evaluate their professional activities, interact with others, and learn from their own and others' experience. Thus, informal learning allows not only to apply but also to develop these skills, increasing the personal effectiveness of teachers. Teachers with a higher level of personal efficiency are better at planning and organizing their work, they are more open to new ideas, experiments and changes. They also show better results in working with students with learning difficulties (Van Veelen, Sleegers \& Endedijk, 2017). Informal learning at school helps teachers to improve their reflection, selforganization, collaboration and social skills (Hanraets, Hulsebosch \& de Laat, 2011).

Unlike formal learning, which is often initiated by school management, informal learning is based on the personal initiative of teachers and is carried out on a voluntary basis. In situations where teachers define their learning goals themselves, make decisions about strategies that will be used and choose partners to achieve these goals with, teachers take more responsibility for their professional development, which increases their motivation to learn. At the same time, it envisages the development of a democratic school management system that stimulates the teachers' participation in the learning process and school management, ensures responsibility for the achievement of school goals and motivates teachers to learn from the experience available in other professional contexts outside the school (Vaessen, van den Beemt \& de Laat, 2014).

The implementation of informal learning consumes less financial resources than the formal learning process, as it takes place in an unscheduled and random way, and the experience and knowledge already accumulated at school is used in the learning process. By learning in a formal way, the knowledge and skills acquired quickly become obsolete and do not meet the professional standard, so teachers must constantly look for new ways how to update these skills (van Veelen, Sleegers \& Endedijk, 2017). The successful process of informal learning at school, on the other hand, involves continuous learning from each other, engaging in day-today duties and collaborating with colleagues. Informal learning at school 
takes place using the infrastructure already available, rather than requires new infrastructure adapted specially for learning purposes.

\section{Challenges with teachers' informal learning at the workplace}

Teachers' informal learning at school is influenced by a variety of factors, such as the school's vision, learning traditions, the infrastructure available for learning, school management, and the school's professional relationships with teachers (Jurasaite-Harbison \& Rex, 2010). Teachers often have limited opportunities to organize their professional development according to their learning needs and goals, which is limited by the formal framework teachers work in. Not always the vision of schools' management is consistent with the teachers' vision of what knowledge they should acquire and what skills they need to develop to become better professionals. This may lead to situations where training activities offered by school leaders are imposed on teachers and do not happen on a voluntary basis.

Unlike formal learning, where the curriculum is strictly defined, the desired outcomes are defined and a specific learning strategy is chosen, informal learning is a less structured process, the results and effects of which are difficult to measure. Ideas and solutions that teachers gain through informal learning do not always produce immediate results: they do not change the teacher's performance and do not improve students' learning outcomes, and their impact takes time to be measured (Evans, 2019). Thus, the impact of informal learning on teachers' practice is difficult to measure and to determine whether and to what extent participation in such activities has improved teachers' professional performance in the classroom.

The professional development of teachers is not related to learning of new content or improving specific skills, but it is also determined by the values and personal attitudes teachers have towards continuous learning and improvement of their professional competence. The learning climate established at school is important: if teachers value mutual cooperation and learning from each other, they will be more willing to engage in informal learning activities (Lohman, 2006). Teachers are used to participate in formal learning activities that is why there is a risk that teachers will not engage with colleagues and will not take a part in collective activities at school, thus reducing their informal learning opportunities.

Informal learning means that teachers acquire new knowledge and skills through active dialogue and collective reflection (Sprott, 2019), which is not possible if teachers support learning that is previously planned, externally managed and structured. Teachers' attitudes towards their professional development are also influenced by their own previous experience as participants in the learning process. Here are important teachers' personal 
perceptions of how new knowledge is acquired and how involved participants should be in order for learning to happen: as a passive listener or an active partner (Rigelman \& Ruben, 2012). Teachers who prefer to learn by acquiring readymade knowledge from other professionals will not participate in informal learning activities where learning is a process of active knowledge construction and includes evaluation of existing practices in the organization for personal growth (Paavola, Lipponen \& Hakkarainen, 2004).

Informal learning requires individual responsibility of teachers for identifying their learning needs, setting learning goals and selecting strategies to achieve these goals. The intellectual capacity of teachers to engage in learning-related issues is not always sufficient. Informal learning relies on teachers' ability to organize and manage their own learning without the direct support of others. However, not all teachers have advanced self-regulation skills (Marsick et al., 2008), which lead them to rely more on the claims of others rather than on their own actions. In the school context, the effectiveness of informal learning is diminished by situations where teachers do not have the necessary knowledge and skills that are expected of them at school and national level (Lohman, 2000), such as the ability to provide, receive and use feedback, learn from their own and colleagues' experiences etc.

As informal learning at school usually happens as a result of teachers' interaction, its effectiveness is determined by the quality of relationships among teachers and past experience of learning from each other. Harris \& Jones (2010) point out that teachers' learning at school is hampered by negative previous experience with non-professional feedback and evaluation of performance after visiting classrooms. The informal learning process at school is not monitored and managed externally, so it is up to colleagues to build mutual trust and respect for long-term informal learning. As a result of negative cooperation, teachers consider informal learning to be an inefficient time-consuming exercise that has no direct impact on their professional performance and student learning outcomes.

In the context of informal learning, good practices are highlighted at school and teachers are learning from each other's previous experiences. However, there is a risk that the exchange of experience may result in an unwanted habits and practices that are difficult to monitor and eradicate (Dale \& Bell, 1999). Informal learning is not guided and monitored, nor does it have clearly defined learning objectives and reference systems, so teachers take on practices that do not always improve students learning experience or help teachers better fulfill their professional responsibilities.

Slotte, Tynjälä \& Hytönen (2004) emphasize that informal learning is not sufficient to provide all the necessary knowledge and skills, because 
not all of the competences are already present in the organization at the time of learning. In the context of teachers' professional development, it means that there is a risk of internal circulation of past experience that preserves existing practice at school, maintains the status quo and does not provide professional growth. Therefore, informal learning needs to be complemented with the elements and content of formal learning (Vaessen, van den Beemt \& de Laat, 2014). Although informal learning provides teachers with specific knowledge and skills, they are linked to a specific situation and are not widely used, as learning in one context is difficult to transfer to another situation (Tynjälä, 2008).

Another limitation of informal learning is that usually such professional development happens unconsciously. Learning participants are unaware of the specific activities and ways in which they have acquired new knowledge, developed skills and attitudes (Simons \& Ruijters, 2004). By learning informally, teachers cannot assess their learning experiences, and it is not clear which cooperation practices should be stimulated and continued at the school, and which cause undesirable effects and should be discontinued. Informal learning usually takes place invisibly and unknowingly, so learners often do not perceive it as a learning (Eraut, 2004). This creates the prerequisites for mutual learning and exchange of experiences at school to be seen as a formality rather than a real opportunity for concrete professional development.

\section{Conclusions}

Teachers' informal learning at workplace can happen in different forms: observing classrooms of colleagues; providing and receiving feedback; engaging in an exchange of experience; reading pedagogical literature; participating in learning groups, etc. However, the potential of informal learning in schools is not being fully exploited, because the teachers' learning has been developed as more formalized, externally managed and structured process, although a large proportion of teachers' professional knowledge and skills are acquired in collaboration with their peers and reflecting on their previous experience.

Summarizing the scientific literature, it can be concluded that in the context of informal learning, teachers themselves choose the objectives and formats of their professional development and partners from which they are going to learn. Such learning improves teachers' personal effectiveness and motivation for learning, promotes school membership, develops reflection, collaboration and feedback skills. Similarly, informal learning allows to adapt the content and process of learning to the real development needs of each teacher, while delegating responsibility for learning outcomes. 
However, in the context of informal learning, there is a risk that teachers take over unwanted professional practices and habits that do not improve their performance or have negative effects on students' learning outcomes. Informal learning is often unintentional and is a by-product of other activities, so it does not always have a specific purpose and a clearly defined criteria for measuring the impact. Such teacher learning is not always recognized as an effective, full-fledged and goal-oriented professional development.

In order to study teachers' informal learning at school, the researchers use qualitative research methods - deep interviews with teachers or school management, analysis of teacher reflection magazines, or focus group discussions -, but they do not always provide objective information about the impact of informal learning on teachers' performance and student learning outcomes.

\section{Questions for futher discussion}

It is important to combine the elements of formal and informal learning in order to ensure goal-oriented and effective professional development of teachers at school. If formal learning provides teachers with new general knowledge and skills, informal learning facilitates their transfer to daily work and application in specific learning situations. However, the challenge for the future is to change the usual practice in schools, where teachers' professional development is seen as a formalized, time-controlled and externally managed learning process, rather than a mutual learning whereby teachers themselves voluntarily take responsibility for setting learning goals and developing an action plan to achieve them.

It is important to strengthen the professional competence of school leadership team in order to create an effective, goal-oriented informal learning system at school. It is the school management's responsibility to demonstrate examples of good practice by learning from colleagues, providing and receiving feedback and facilitating regular exchange of experiences between teachers. Therefore, the question is whether the school management's competence in designing such a system is sufficient for informal learning to become a daily practice rather than a formality without a direct impact on teachers' performance and student learning outcomes.

The prerequisite for informal learning is the personal motivation of teachers and their interest in continuous learning, which is determined by their previous learning experience and attitudes towards their professional development. In order to develop their competences through informal learning, teachers must be prepared to use the best practices available at 
school, learn from other professionals, and set self-directed learning goals. In the context of the teachers' professional development, it is important to think about development of collaborative, planning and reflection skills so that informal learning becomes a resource for teachers' personal growth and school can be transformed into an effective learning organization.

\section{References}

Carney, S. (2000) Getting the most out of school-based initial teacher education: professional development possibilities for teachers. Improving Schools. Volume 3, Number 2, 31-37.

Cheng, C. K. E. (2017) Managing school-based professional development activities. International Journal of Educational Management. Vol. 31, Issue 4, 445-454.

Cross, J. (2007) Informal learning: Rediscovering the natural pathways that inspire innovation and performance. San Francisco: Pfeiffer, John Wiley.

Dale, M. \& Bell, J. (1999) Informal learning in the workplace. DfEE Research Report. No. 134, London: Department for Education and Employment.

Desimone, L. M. (2009) Improving impact studies of teachers' professional development: toward better conceptualizations and measures. Educational Researcher. 38 (3), 181-199.

DiPaola, M. \& Hoy, W. K. (2014) Improving instruction through supervision, evaluation, and professional development. Charlotte, NC: Information Age.

DuFour, R., \& Eaker, R. (1998) Professional learning communities at work: Best practices for enhancing student achievement. Bloomington, IN: National Educational Service.

Eraut, M. (2004) Informal learning in the workplace. Studies on Continuing Education. 26 (2), 173-247.

Evans, L. (2019) Implicit and informal professional development: what it looks like, how it occurs, and why we need to research it. Professional Development in Education. Vol. 45, No. 1, 3-16.

Hanraets, I., Hulsebosch, J., de Laat, M. (2011) Experiences of pioneers facilitating teacher networks for professional development. Educational Media International. Vol. 48, No. 2, 85-99.

Harris, A., Jones, M. (2010) Professional learning communities and system improvement. Improving Schools. Volume 13, Number 2, 172-181.

Hoekstra, A., Korthagen, F. (2011) Teacher Learning in a Context of Educational Change: Informal Learning Versus Systematically Supported Learning. Journal of Teacher Education. 62 (I), 76-92.

Jurasaite-Harbison, E. \& Rex, A. L. (2010) School cultures as contexts for informal teacher learning. Teaching and Teacher Education. 26, 267-277.

Jurasaite-Harbison, E. \& Rex A. L. (2013) Teachers as informal learners: workplace professional learning in the United States and Lithuania. Pedagogies: An International Journal. Vol. 8, No. 1, 1-23.

Kwakman, K. (2003) Factors Affecting Teachers' Participation in Professional Learning Activities. Teaching and Teacher Education. 19 (2), 149-170. 
Lave, J. \& Wenger, E. (1991) Situated learning: Legitimate peripheral participation. Cambridge: Cambridge University Press.

Lohman, C. M. (2000) Environmental Inhibitors to Informal Learning in The Workplace: A case Study of Public School Teachers. Adult Education Quarterly. Vol. 50, No. 2, 83-101.

Lohman, C. M. (2006) Factors Influencing Teachers' Engagement in Informal Learning Activities. Journal of Workplace Learning. Vol. 18, Issue 3, 141-156.

Lohman, M. C., \& Woolf, N. H. (2001). Self-initiated learning activities of experienced public school teachers: Methods, sources, and relevant organizational influences. Teachers and Teaching: Theory and Practice. 7, 59-74.

Lund, L. (2018) When school-based, in-service teacher training sharpens pedagogical awareness. Improving Schools. 1-15.

Marsick, V. J. \& Watkins, K. E. (1990) Informal and incidental learning in the workplace. London: Routledge.

Marsick, V. J., Watkins, K. E., Callahan, W. M., Volpe M. (2008) Informal and Incidental Learning in the Workplace. In Handbook of Research on Adult Learning and Development. London: Routledge, 570-600.

McLagan, A. P. (2008) Competencies and the Changing World of Work. In Biech, E. (Ed.) ASTD Handbook for Workplace Learning Professionals. ASTD Press. 127-146.

McNally, J., Blake, A., Reid, A. (2009) The Informal Learning of new teachers in school. Journal of Workplace Learning. Vol. 21, Issue 4, 322-333.

Paavola, S., Lipponen, L., \& Hakkarainen, K. (2004). Models of innovative knowledge communities and three metaphors of learning. Review of Educational Research. 74, 557-576.

Patton, K., Parker, M., Tannehill, D. (2015) Helping Teachers Help Themselves: Professional Development That Makes a Difference. NASSP Bulletin. Vol. 99 (I), 26-42.

Poell, R. F. (2006) Organizing learning projects whilst improving work: Strategies of employees, managers, and HRD professionals. In Streumer, J. N. (Ed.) Work-related learning. Dordrecht: Springer, 151-180.

Richter, D., Kunter, M., Klusmann, U., Ludtke, O., Baumert, J. (2011) Professional development across the teaching career: Teacher's uptake of formal and informal learning opportunities. Teaching and Teacher Education. 27, 116-126.

Rigelman, N. M., Ruben, B. (2012) Creating foundations for collaboration in schools: Utilizing professional learning communities to support teacher candidate learning and visions of teaching. Teaching and Teacher Education. 28, 979-989.

Simons, P. R. J. \& Ruijters, M. C. P. (2004) Learning professionals: towards an integrated model. In Boshuizen, H. P. A., Bromme, R. \& Gruber, H. (Eds.). Professional learning: gaps and transitions on the way from novice to expert. Dordrecht: Kluwer Academic Publishers, 207-229.

Slotte, V. \& Tynjälä, P. (2003) Industry-university collaboration for continuing professional development. Journal of Education and Work. 16 (4), 445-464.

Slotte, V., Tynjälä, P. \& Hytönen, T. (2004). How do HDR practitioners describe learning at work? Human Resource Development International. 7(4), 481-499.

Sprott, A. R. (2019) Factors that foster and deter advanced teachers' professional development. Teaching and Teacher Education. No. 77, 321-331. 
Tammets, K., Pata, K., Laanpere, M. (2013) Promoting Teachers' Learning and Knowledge Building in a Socio-Technical System. The International Review of Research in Open Distance Learning. Vol. 14, No.3, 251-272.

Tynjälä, P. (2008) Perspectives into learning at the workplace. Educational Research Review. No. 3, 130-154.

Vaessen, M., van den Beemt, A., de Laat, M. (2014) Networked professional learning: relating the formal and the informal. Frontline Learning Research 5. Special Issue Learning through Networks. 56-71.

Van Veelen, R., Sleegers, J. C. P., Endedijk, D. M. (2017) Professional Learning Among School Leaders in Secondary Education: The Impact of Personal and Work Context Factors. Educational Administration Quarterly. Vol. 53 (3), 365-408.

Vanblaere, B., Devos, G. (2016) Relating school leadership to perceived professional learning community characteristics: A multilevel analysis. Teaching and Teacher Education. No. 57, 26-38.

Wenger, E., McDermott, R., Snyder, W. M. (2002). Cultivating Communities of Practice. Boston, MASS: Harvard Business School Press.

Wideen, M., Mayer-Smith, J., \& Moon, B. (1998). A critical analysis of the research on learning to teach: Making the case for an ecological perspective on inquiry. Review of Educational Research. 68, 130-178

Wohlfahrt, U. M. (2018) Primary Teacher Education in Rural Cameroon: Can Informal Learning Compensate for the Defiencies in Formal Training? Africa Education Review. $15: 3,1-20$. 